\title{
Accounting and analytical base for management of logistic flows in tourism business
}

\author{
Olena Prokopishyna ${ }^{1 *}$, Natalia Kozubova ${ }^{2}$ and Karina Satusheva ${ }^{1}$ \\ ${ }^{1}$ Simon Kuznets Kharkiv National University of Economics, Department of accounting and business \\ consulting, 61001 Kharkiv, Ukraine \\ ${ }^{2}$ Simon Kuznets Kharkiv National University of Economics, Department of tourism, 61001 Kharkiv, \\ Ukraine
}

\begin{abstract}
The paper grounds that the existing potential of the tourism industry of Ukraine can be realized through the introduction of efficient logistic approaches for the development of tourism and recreation and management of tourist enterprises. Based on modern knowledge of the theory and practice of tourism management, a logistic strategy in tourism business serves for the creation of tourism product which is highly competitive in the global market due to implementation efficient management decision upon each component of the logistics system of the company. The paper reveals the essence and major functions of accounting and analytical subsystem of logistic management of tourism companies that enables to shorten the duration of the operating cycle, improve the quality and expand the range of travel services, and increase the flexibility of the travel service. The paper concludes that efficient accounting and analytical subsystem of logistic management gives travel companies wide opportunities to gain competitive advantages on global travel market.
\end{abstract}

\section{Introduction}

Scientific guidelines on logistics are very useful for the development of tourism industry in Ukraine as well as of highly competitive world market of travel services. Application of logistic management principles can be extremely useful in the tourism and recreation industry, due to accumulation of experience in the creation, implementation, monitoring and control of chain supplies. In the case of the formation of a supply chain in the tourism industry, experienced and professional knowledge in the cargo and passengers transport system is vitally important. A highly competitive tourism market requires high quality service, which is a priority area in finding ways to improve tourism logistic.

\section{Discussion}

\footnotetext{
* Corresponding author: elena_prokopishin@ukr.net
} 


\subsection{The essence and significance of logistics for the management of a travel company}

Modern theory treats logistics systems as managerial systems for material, information, finance and human flows. The human flows are not generally accepted in the field of logistics, but may be successfully qualified as the object of logistic science according to the theory of tourism resources management. The application of the term "logistics" in tourism management, is considered as an effective method for managing flow processes of tourists, as well as accompanying information and financial flows, with the possibility of optimizing the costs involved in the production of tourism product and customer service during travel.

Tourist logistics can be understood as a science of planning, controlling and managing operations that are carried out in the process of forming, bringing the tourist product to the consumer, as well as in the process of transferring, storing and processing information. In turn, the logistic management of tourism activities is a purposeful impact on the coordination and synchronization of the processes of formation of flows of tourists and their service [1].

Being in compliance with the general principles of management of human flows, tourist flows have their own peculiarities. Management of tourist human flows is carried by tourism business logistics, aimed at managing human and associated flows, in contrast to traditional logistics flows. In the tourist area, the priority is the human flow, which submits the analysis and is predicted, that enables planning and forecasting of necessary material, energy, financial and information resources.

Human flows are divided into flow of actors (providers) and flow of service objects (consumers). In the composition of the tourist flow 4 categories of tourists and the corresponding streams may be distinguished: domestic tourism (resident visitor), inbound tourism (non-resident visitor), outbound tourism (resident visitor), transit (non-resident visitor) [2]. The foreign tourism is essential for a national recreational complex. It contributed to the development of infrastructure, investments and improvement of the quality of travel services to satisfy high requirements of world class consumers.

The definition and study of the features of tourist flows is important for elimination of negative factors of tourism development as the decline in the quality of services, reduction of the number of regular customers; it also provides the opportunity to establish tourist flows, and develops mechanisms that can create cyclic and nonstop tourist flows, despite the qualitative characteristics of tourists.

All tourist movements form an uninterrupted human flow that combines subjects and objects, as well as concomitant flows. Distinctive feature of flows of consumers is that they simultaneously act as objects of management and service, carriers of information and material resources. As the management of human flows in tourism takes place during the provision of services provided throughout the period, and management should ensure that this procedure is carried out in compliance with authorities, legislation and moral principles of travel companies activities.

Management of human flows of tourism business requires the development and implementation of a comprehensive logistics strategy.

\subsection{Logistic strategy for development of tourism business}

The complex and multilevel logistics system of the producer and the organizer of tourism differs not only in terms of activities, but also in terms of the degree of integration of business, the volume of consolidation. Based on the analysis of the logistics management system in the subjects of the tourism industry, most enterprises should look for reserves and ways to improve logistics management, create a structured logistic model, taking into account modern scientific developments, international experience, managerial innovations 
that require certain enterprise managers to have certain knowledge and the ability to organize the process of providing people with knowledge, desires, opportunities, as well as creative behaviour in conditions of fierce competition.

According to the researchers, the logistics strategy is a long-term, qualitatively defined direction of logistics development concerning the forms and means of implementation in the enterprise of interfunctional and inter-organizational coordination and integration, formulated by the higher management of the enterprise in accordance with its corporate goals $[3,4]$ and aimed at optimizing the resources of the company when managing the main and concomitant flows $[5,6]$. Strategic goals in logistics are achieved by establishing its connection with the basic principles of corporate governance.

In the case of developing a logistics strategy, the starting point may be the definition of a common corporate strategy, that is, a higher level strategy with respect to logistics. Conceptually, the principles and requirements of the corporate strategy are developed taking into account the public needs, needs of consumers, personnel, business owners and business partners. The higher-level strategies set goals and context, which takes into account all the logistics solutions [7]. The experience of countries with a developed market economy shows that logistics plays an important role in shaping a common corporate strategy. This is especially true for companies that practice advanced technologies based on integrated logistics networks.

The unceasing process of globalization, together with the liberalization and expansion of the international tourism market, has led to unexpected losses in market share for developed touristic countries. New directions are often counted on resources that are little known and, therefore, uniquely attractive. They are able to introduce new products and services competitive for the international market $[8-10]$. Due to the low level of development, new tourist countries were able to obtain a temporary competitive advantage in the form of low labour costs and favourable exchange rates of the national currency relative to convertible ones. Consequently, despite the benefits that traditional tourism countries derive from the high level of development of tourism infrastructure, specialization in tourism and competitive experience, their ability to compete at a low price due to high wages and exchange rates, which slows the economic development of tourism in these countries and prompts the invention and introduction of innovations.

Service Response Logistics is defined as a process of coordinating the logistics operations necessary to provide excursion and accompanying tourism services in the most efficient way in terms of costs and customer satisfaction. This approach is the main strategic element of management of many enterprises that provide tourist services. The critical elements of this approach are the acceptance of travel services and monitoring of the provision of tourist services. Flows of tourist services as well as material flows are distributed in a certain delivery environment, in which there are links in the logistics system, logistics channels, circuits, etc. This network needs to be built in such a way as to maximally meet customer requirements for service levels. For storage of goods and stocks at certain tourist enterprises designated warehouses. The travel company bears some expenses related to the storage of warehouses and warehousing operations. They are part of the logistics costs. Therefore, warehouse operations need to be considered not in isolation, but as an integrated component of the logistics chain. Only this approach is a guarantee of successful fulfilment of the main functions of the composition and achievement of a high level of profitability of sales of a tourist product. The purpose of creating warehouses in logistics systems is not the conservation of material resources, but the transformation of material flow parameters for their most effective use.

The marketing logistics of tourist products is an integral part of the overall logistics system, which ensures the most effective organization of distribution of products ready for use. The functions of marketing logistics are to distribute and promote the tourist product 
through the channels of commodity circulation, supply of the product oriented to the needs of consumers (according to terms of service, quality, quantity and price), optimization of costs associated with the operation of the logistics system and commercial marketing activities, the use of optimal information marketing systems.

Logistics should be engaged in the organization of the search and purchase of necessary goods of the appropriate quality and at the lowest prices. An analysis of possible logistics costs plays an important role in improving the logistics efficiency of logistics. The optimization of the logistics chain is influenced by both external and internal factors. External relations should include the relationship of entrepreneurs with creditors and suppliers. Internal factors are associated with a different understanding of the optimal activity of chain links, the need for economic compromises between different divisions of firms. Successful procurement involves the availability of a wide range of information on the state of the markets. For the market research, detailed information is regularly selected and evaluated to determine market capacity and create prerequisites for optimizing procurement.

The essence of information logistics in tourism is the organization of data flows that accompany the tourist flow, and is an essential link that connects the supply, production and sales. Information logistics operates with a set of economic information in the horizontal and vertical directions, in internal and external coordination and requires the appropriate infrastructure. Under the information infrastructure of the logistics system in tourism is understood a set of interrelated tools and methods that provide information preparation, namely: data collection and their initial processing, control of reliability, storage and transmission of information, its updating, correction and presentation.

The information flow in the tourism logistics is the main component, as it provides interconnection between the links of the logistics chain "travel agent - tour operator material and technical base - recreational and tourist resources" through the control and accounting of tourism, material and financial flows. Rational and coherent implementation of all these functions necessitates the creation of a special accounting and analytical subsystem of management of logistics flows of tourism business, which should include functional and security subsystems. Consequently, the accounting and analytical subsystem of management of logistic flows of tourism business is a set of organized and interrelated processes regulating the activities of tourism enterprises. In the logistic information system of tourism, phenomena of vertical and horizontal integration are often observed. The essence of vertical integration is the availability of information links between the tour operator, travel agents and suppliers of tourist products. Horizontal integration represents the information links of tourist firms on the same level.

The functioning of the accounting and analytical subsystem of management of logistic flows of tourism is related to the implementation of certain functions, including planning, coordination, maintenance and control. Execution of these functions makes it possible to coordinate work between different logistic elements.

In the organizational structure of the accounting and analytical subsystem of management of the logistics flows in the tourism business, following subsystems may be distinguished: management of orders processes, implementation of scientific research and communication, the formation of logistics solutions, creation of initial forms and reports. These subsystems are interconnected and provide information and computer support for the whole logistics system at the micro and macro levels. The subsystem of process management of orders provides direct contact with the consumer in the process of formation and execution of the order; the subsystem of scientific research and communication performs analysis and predicts the influence of the external and internal environment of the organization; The subsystem of logistics decision making uses computer databases and analytical models to optimize decision making. 
The functioning of the accounting and analytical subsystem of management of tourism logistics flows should be based on the following principles: reliability and completeness of information (for rational and reasonable decision-making by the logistics manager); the accuracy of the source information (is important in determining the amount of available and required resources); timeliness (information should be received on time in a timely manner, since it is necessary for all logistic functions); orientation (information in the logistics system should be aimed at solving certain problems); flexibility (information must be adapted for use in different forms and for different users of information).

Implementation of the accounting and analytical subsystem of management of logistics flows in the tourist enterprise enables: to increase the efficiency of its work, to achieve a high level of service for customers and to provide effective control; to provide a modern approach to the management of sales processes and organization of tourist services; monitor the effectiveness of tourist services; carry out an analysis of the profitability of the tourism business; to increase the efficiency of the pricing policy of the tourist enterprise, and so on.

The accounting and analytical subsystem of management of logistic tourism flows also provides an opportunity to quickly and qualitatively create a package of new services for organizing events of different nature in order to maximally meet the needs of the client. An important direction of its application is the optimization of the use of profit, which, in turn, gives the opportunity to gain competitive advantage and significant increase in revenues from the work in real time, constantly analyzing booking information, seasonal fluctuations, segments specifics, price levels and tariffs on market of tourist services.

Application of the accounting and analytical subsystem of management of logistic flows is possible both for separate tourist firms, and for the network of enterprises of this branch, which has a whole set of data.

The advantage of using the accounting and analytical subsystem of logistics flow management is the ability to conduct flexible marketing and pricing policies, as well as the maximum coverage and aggregation of all customer inquiries. So, using such a system, a travel company can effectively sell tourist products based on the analysis of trends and market demands, constantly monitor the conditions of their services sales, adjusting them in accordance with the market conditions in any segment, which, in turn, will be to promote the quality of services and the level of profitability of the activity.

The effectiveness of the logistics systems of the tourist enterprise in the most general form can be represented as a systemic economic task, aimed at solving the problem of achieving high quality of its work. Regarding logistics, systematic means that all participants in tourist flows are regarded as part of a single whole process, and the process itself is an integrated problem of all participants.

\section{Conclusions}

Implementation and use of the accounting and analytical subsystem of management of logistic flows in tourism business allows: to create a unified system of accounting and control of the formation and movement of a tourist product; reduce the intervals of formation, promotion and realization of the tourism product; to automate the processes of accounting and control of financial and information flows during tourist services; shorten the time and improve the quality of service of consumers of tourist product; reduce the amount of documentation and significantly reduce the number of errors in the accounting records.

The objects of the accounting and analytical subsystem management of the logistics flows of the tourism business are the processes of formation, promotion and realization of the tourism product, as well as related financial and information flows. These complex 
processes require the formation and analysis of information on: the estimated contingent of tourist product consumers (business, sports, recreational, educational and other tours); types of tourist products that are in greatest demand at present or in the near future (winter or summer season); conditions of accommodation (hotels, restaurants, holiday houses, camping sites); tourist services and their logistical support; components of marketing; operating tariffs; quality and reliability of the services rendered.

The main functions of the accounting and analytical subsystem management of the logistics flows of the tourism business are: operational analysis, control and management of the processes of formation, promotion and implementation of tourism product, as well as strategic planning and forecasting of tourism organizations; operative transfer (reception) of necessary volume and quality of information at the given time and in the right place; operational control of the movement (movement) of tourists and tourist product; Integration of separate functioning tourism information systems (local, regional, transcontinental networks, etc.) into a single logistic information system; calculation and organization of the financial reserve in case of force majeure situations on the basis of analysis and forecasting of the development of negative trends in the tourism sector.

Implementation of modern methods of logistic management in business practice can reduce inventory, reduce production and circulation costs, reduce the duration of functional logistics cycles, and improve customer service. The current state of the consolidation of the tourism business, globalization processes, restructuring, mergers and acquisitions, grouping into strategic alliances adds value to the corporate logistics strategy as a highly architectural managerial form, which in essence is innovative and requires significant intra-firm coordination. Thus, the management of human flows in the field of tourism is carried out through the management of material, financial and information flows. The main task of the tourism logistic is development and application of certain mechanisms to ensure the cyclicality of the specified flows and their efficiency in the competitive world market.

The paper was funded by a grant "Formation of the scientific and technological platform for the harmonization of the socio-economic interests of Ukraine in the world economic space". (No. 0116U004521) from the Ministry of Education and Science of Ukraine

\section{References}

1. R. Baggio, R. Sainaghi, Complex and chaotic tourism systems: towards a quantitative approach, IJCHM 6, 840 (2011)

2. S. Cole A logistic tourism model: resort cycles, globalization, and chaos, ATR 4, 689 (2009)

3. O. Prokopishyna, N. Kozubova Organizational support for internal tourism based on rational use of Ukraine tourist and recreational resources, NVIU 13, 54 (2015)

4. J. Zhang, C. Jensen Comparative advantage: explaining tourism flows, ATR 1, 223 (2007)

5. W. Zhao, J. Ritchie, C. Echtner Social capital and tourism entrepreneurship. ATR 38(4), 1570 (2011).

6. L. Oigenblick, A. Kirschenbaum, Tourism and immigration: Comparing alternative approaches. ATR 29(4), 1086 (2002).

7. T. Tyrrell, R. Johnston The economic impacts of tourism: a special issue. JT, 45(1), 3(2006).

8. D. Hughes, M. Shields Revisiting tourism regional economic impact: Accounting for secondary household employment. RRS, 37(2), 186 (2007)

9. S. Smith New developments in measuring tourism as an area of economic activity. TORLT 1, 225 (2000).

10. U. Avci, M. Madanoglu, F. Okumus, Strategic orientation and performance of tourism firms: Evidence from a developing country. TM, 32(1), 147 (2011). 